\author{
凹凸のある壁の流れに及ぼす効果 \\ 山本 恭二 $* 1$. 谷脇 充浩 $* 2 \cdot$ 武内 秀樹 $* 1 \cdot$ 百武 徹 $* 1$

\section{Effect of Surface Grooves on a Channel Flow} \\ Kyoji YAMAMOTO*1, Mitsuhiro TANIWAKI*2, \\ Hideki TAKEUCHI*1 and Toru HYAKUTAKE*1 \\ ${ }^{* 1}$ Department of Mechanical Engineering, Faculty of Engineering, Okayama University, \\ 3-1-1 Tsushima-naka, Okayama 700-8530, Japan \\ *2Mechanical Engineering, Niihama National College of Technology, 7-1 Yagumo, Niihama 792-8580, Japan
}

(Received November 25, 2005, Accepted February 11, 2006)

\begin{abstract}
Effects of surface grooves on the rarefied gas flow through a channel are investigated numerically using the linearized B-G-K equation. One wall of the channel has rectangular grooves engraved periodically parallel or normal to the flow direction, and the other wall is flat. Couette and Poiseuille flows are analyzed. It is shown that in case of normal grooves, the flux through the channel has a minimum when the depth of the groove is about half of its width. For parallel grooves, the flux is considerably low compared with that of the smooth walls of the channel when the groove width and pitch are comparatively smaller than the channel width.
\end{abstract}

\section{1. はじめに}

チャネルや管を通る希薄気体の流れの研究は基本的で重要 であることから，古くから行われているところであるが，最 近のマイクロマシンやMEMS (micro-electro-mechanical systems）の発達に伴い, 微小チャネルや細管を通る流れの 研究が一層重要になってきている. そのような微小管内の流 れでは, 壁面の微小形状が管内流量や熱伝達量に影響を及ぼ すことが考えられる.このような壁面の微小形状の重要性 は, これ迄，壁面粗さの管内流に対する影響を調べるという 観点から研究がなされてきた. 宇佐美ら ${ }^{1)}$ は，二次元スリッ トの, また, 杉山ら ${ }^{2}$ は, 有限長さの平行平板間の圧力差に よる流れに対し, 壁面粗さの影響を, 粗さを三角柱形状にモ デル化することにより調べている，また，Sun と Faghri3) は, 矩形形状の粗さモデルを用いることにより, 二次元チャ ネル内の圧力差による流れを, 比較的小さなクスーセン数に 対して調べている.これらの研究では, 粗さは流れに垂直に 設置されている. 更に, Sawada ら ${ }^{4)}$ は, 三角錐形状のモデ ルを用いることにより粗さの影響を調べている.

表面の微小な凹凸が流れに及ぼす影響を調べるため, 著者 ら5)は, 表面が矩形形状溝を持つ無限長のチャネルに対し,

チャネルに沿う圧力勾配（ポワゾイユ流）と温度勾配 (thermal creep flow) による流れを, 矩形溝が流れに平行に ある場合, 及び垂直にある場合に対して調べ, 溝の谷の幅と 山の幅が共に同じ程度に小さい場合に, 流量に対し, 大きな 影響のあることを明らかにした。本研究では, チャネル壁の 一方には矩形溝の凹凸があり，もう一方は平らな壁である場 合に，一方の壁が他方に対し平行に移動する場合の流れ（ク エット流）とチャネルに沿う圧力勾配により生ずる流れ（ポ ワゾイユ流）を解析し，壁面の凹凸が流れに及ぼす影響を調 ベるものである.

*1 岡山大学工学部機械工学科 (テ700-8530 岡山市津島中 3-1-1)

*2 新居浜工業高等専門学校 (厂792-8580 新居浜市八雲町 7-1)

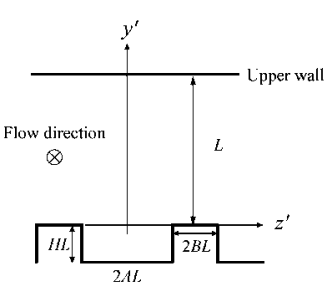

(a) paralleI groove

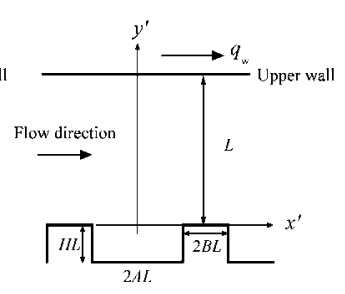

(b) normal groove
Fig. 1 Wall configuration.

\section{2. 解析方法}

距離 $L$ だけ離れた二枚の無限平板間の希薄気体について 考える. 下壁面が $x^{\prime}-z^{\prime}$ 面, $y^{\prime}=L$ が上壁面になるように座標 系 $\left(x^{\prime}, y^{\prime}, z^{\prime}\right)$ を取る. 下壁面には，Fig. 1 に示すように， 周期的な矩形溝があり, 上壁面は平らであるとする. 溝は流 れに平行な場合（平行溝：Fig. 1(a)）と垂直な場合（垂直 溝 : Fig. 1(b)）の 2 種類考えるものとする. 溝の山から上 壁迄の距離を $L$ とし, 溝の幅を $2 A L$, 深さを $H L$, 堤の幅 を $2 B L$, 溝のピッチを $2(A+B) L$ とする. 流れとして, 上 壁が速度 $q_{\mathrm{w}}$ で移動する場合のクエット流と， $x^{\prime}$ 方向に $p^{\prime}=$ $p_{0}\left(1-\alpha x^{\prime} / L\right)$ の一定の圧力勾配のあるポワゾイユ流を取り 上げる，ここで, $p^{\prime}=k n^{\prime} T^{\prime}$ は圧力, $n^{\prime}$ は数密度, $T^{\prime}$ は温度 であり, 添字 0 は基準点 $x^{\prime}=0, y^{\prime}=L / 2$ での量を表す。 また, $k$ はボルツマン定数, $\alpha$ は圧力勾配であり, $\alpha=-\left(L / p_{0}\right)$ $\partial p^{\prime} / \partial x^{\prime}$ となる. 本解析においては, いわゆる $\mathrm{B}-\mathrm{G}-\mathrm{K}$ 方程 式6)を用い, また, 壁面の境界条件としては, 拡散反射条件 を用いる. 上壁速度 $q_{\mathrm{w}}$ や圧力勾配 $\alpha$ は十分小さいとし, 基 礎方程式並びに境界条件を線形化する。

平行溝の場合, 流速は $x^{\prime}$ 方向に変化しないと考えられ る. また, 温度一定と仮定される. 従って, 次のような基礎 式を得る。

$$
K\left(V \frac{\partial \Phi}{\partial Y}+W \frac{\partial \Phi}{\partial Z}\right)=2 U Q_{\mathrm{X}}-\Phi+K \alpha U
$$




$$
\begin{aligned}
& Q_{\mathrm{X}}=\int U \Phi E d \boldsymbol{V}, \quad \Sigma=-\alpha X, \quad \Theta=0, \\
& K=\frac{C_{\mathrm{m}}}{\lambda L}=\frac{\sqrt{\pi} l}{2 L}, \quad E=\pi^{-3 / 2} \exp \left(-\boldsymbol{V}^{2}\right) .
\end{aligned}
$$

ここで, $n_{0} C_{\mathrm{m}} E(1+\Phi)$ は分子速度分布関数, $C_{\mathrm{m}}=\sqrt{2 k T_{0} / m}$ は最確速度, $m$ は分子の質量, $C_{\mathrm{m}} \boldsymbol{V}=C_{\mathrm{m}}(U, V, W)$ は分子 速度, $\boldsymbol{x}^{\prime}=L \boldsymbol{X}=L(X, Y, Z)$ は座標, $n_{0}(1+\Sigma)$ は数密度, $T_{0}(1+\Theta)$ は温度, $p_{0}(1+\Sigma+\Theta)$ は圧力, $C_{\mathrm{m}} \boldsymbol{Q}=C_{\mathrm{m}}\left(Q_{\mathrm{X}}, Q_{\mathrm{Y}}\right.$, $0)$ は流速, $\lambda$ は衝突頻度, $l$ は分子の平均自由行路, $K$ はク ヌーセン数である.

垂直溝に対しては，次式が得られる.

$$
\begin{aligned}
& K\left(U \frac{\partial \Phi}{\partial X}+V \frac{\partial \Phi}{\partial Y}\right)= \Sigma+2 U Q_{\mathrm{X}}+2 V Q_{\mathrm{Y}} \\
&+\left(\boldsymbol{V}^{2}-\frac{3}{2}\right) \Theta-\Phi+K \alpha U, \\
& \Sigma=\int \Phi E d \boldsymbol{V}, \quad\left(Q_{\mathrm{X}}, Q_{\mathrm{Y}}\right)=\int(U, V) \Phi E d \boldsymbol{V}, \\
& \frac{3}{2}(\Sigma+\Theta)=\int \boldsymbol{V}^{2} \Phi E d \boldsymbol{V} .
\end{aligned}
$$

壁面の境界条件は，

式(1)に対し,

下壁では $\Phi=0$, 上壁では $\Phi=2 U\left(q_{\mathrm{w}} / C_{\mathrm{m}}\right)$

$$
[\text { ただし }(\boldsymbol{V} \cdot \boldsymbol{n}>0)] \text {. }
$$

式(4)に対し,

下壁では $\Phi=\Sigma_{\mathrm{wL}}(\boldsymbol{x})$,

上壁では $\Phi=\Sigma_{\mathrm{wU}}(\boldsymbol{x})+2 U\left(q_{\mathrm{w}} / C_{\mathrm{m}}\right)$

$$
\text { [ただし }(\boldsymbol{V} \cdot \boldsymbol{n}>0), \boldsymbol{Q} \cdot \boldsymbol{n}=0 .] \text {. }
$$

ここで， $\boldsymbol{n}$ は壁面での流路向き単位べクトルである. 式 (1) 及び(4)の数值計算法としては，主として二次の空間差分法 と分子速度離散座標法を用いる。

チャネルを通る流体の流量は，平行溝では溝の一ピッチ当 り, また，垂直溝では $z^{\prime}$ 方向単位長さ当り

$$
M=\int_{S} \int_{\mathrm{m}} C_{\mathrm{X}} d S \text {. }
$$

ここで, $S$ はチャネルの断面積であり, 次のようになる.

$$
\left.\begin{array}{ll}
S=2(A+B+A H) L^{2} & : \text { 平行溝, } \\
S=L & \text { : 垂直溝. }
\end{array}\right\}
$$

無次元流量を次のように定義する.

$$
\left.\begin{array}{c}
F_{\mathrm{C}}=\frac{M}{q_{\mathrm{w}} S}: \text { クエット流, } \\
F_{\mathrm{P}}=\frac{M}{\alpha C_{\mathrm{m}} S}: \text { ポワゾイユ流. }
\end{array}\right\}
$$

平行溝の場合，断面の凹凸により断面積が変化し，それによ る流量の変化が現れる．ここでは，壁の形状の違いが流量に 及ぼす影響のみに着目しその変化を見るため, 単位断面あた りの流量でもって無次元流量を表している.

クエット流とポワゾイユ流が共存する場合に，全流量が0 であるとすると, 壁速度と圧力勾配の間には次の関係が得ら れる。

$$
R=\left[\frac{L}{p_{0}} \frac{\partial p^{\prime}}{\partial x^{\prime}}\right] /\left[\frac{q_{\mathrm{w}}}{C_{\mathrm{m}}}\right]=\frac{F_{\mathrm{C}}}{F_{\mathrm{P}}} .
$$

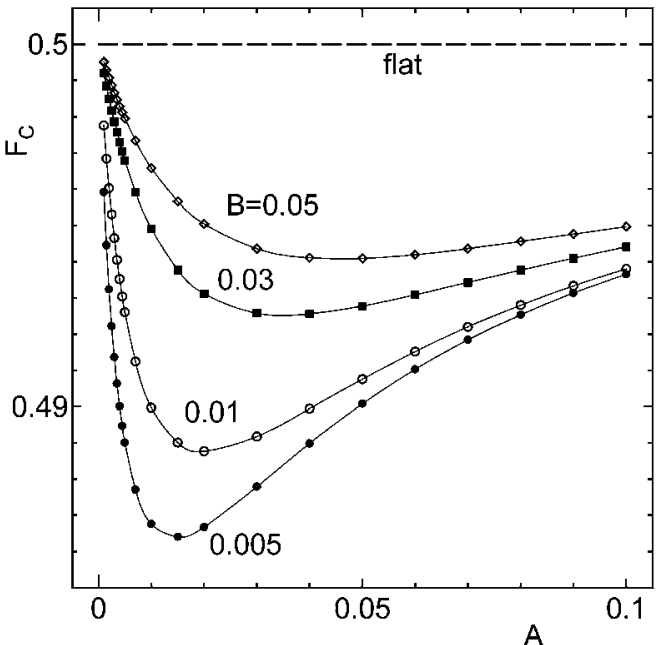

Fig. 2 Flux versus $A$ for Couette flow: parallel groove, $H=$ $0.05, K=0.1$.

\section{3. 結果}

得られた結果のうち, チャネル内の流量が, 壁面の凹凸に より, どのように変化するかということに着目して述べる.

\section{1 クエット流れ}

溝のある下壁が静止し，上壁が速度 $q_{\mathrm{w}}$ で移動するクエッ ト流の結果を示す.

\section{1 .1 平行溝の場合}

まず最初に，上壁の移動方向と下壁の溝方向が一致する平 行溝に対する結果について述べる. 溝の深さが $H=0.05$, ク ヌーセン数が $K=0.1$ の場合に, 流量 $F_{\mathrm{c}}$ が $A$ について, ぞ のように変化するかをいくつかの $B$ に対し Fig. 2 に示す. この図及び以下の図に招いて, 点線は下壁が平板の場合を示 している，Bのいずれの場合にも, 流量は下壁が平板の場合 よりも小さく, $A \rightarrow 0$ すなわち, 溝の幅が 0 に近づくと, 当 然平板值に近づくことが分かる. また, 流量は, $A$ が 0 か ら増加するにつれて減少し, 最小值を取った後増加するこ と, また, この最小值は堤の幅 $B$ が小さい程小さいことが 見られる。すなわち， $B<A$ を保ちながら $A$ が小さくなる 程，流量は下壁が平板の場合の值より大きく減少する。な お, 今の場合は, 溝のある下壁が静止し, 平板である上壁が 移動しているが, 逆に, 溝のある壁が速度 $q_{\mathrm{w}}$ で移動し, 平 板壁が静止している場合の流量は $1-F_{\mathrm{C}}$ となり, 溝のある壁 の移動により, 両壁共平板である場合より流量は増加する.

Fig. 3 には， $A=B=0.01 の$ 場合に， $F_{\mathrm{c}}$ が $K$ に対してど のように変化するかを，いくつかの $H$ に対して示してい る. 下壁が平板の場合である場合の $F_{\mathrm{C}}$ は, $\mathrm{K}$ に対し一定值 をとる．溝が深くなるにつれて流量は減少するが，これは， 溝の部分での流速の減少に伴い, 全断面に渡る平均流量が減 少することによるものである。 また，一定の $\mathrm{H}$ における $\mathrm{K}$ による流量の変化は比較的小さいが, 下壁を平板とした場合 の流量からの減少值は，K が小さい程僅かに大きい。

3.1 .2 垂直溝の場合

次に，上壁の移動速度と溝の方向とが垂直になっている場 合の結果について述べる. Fig. 4 に， $F_{\mathrm{C}}$ の $A$ に対する変化 


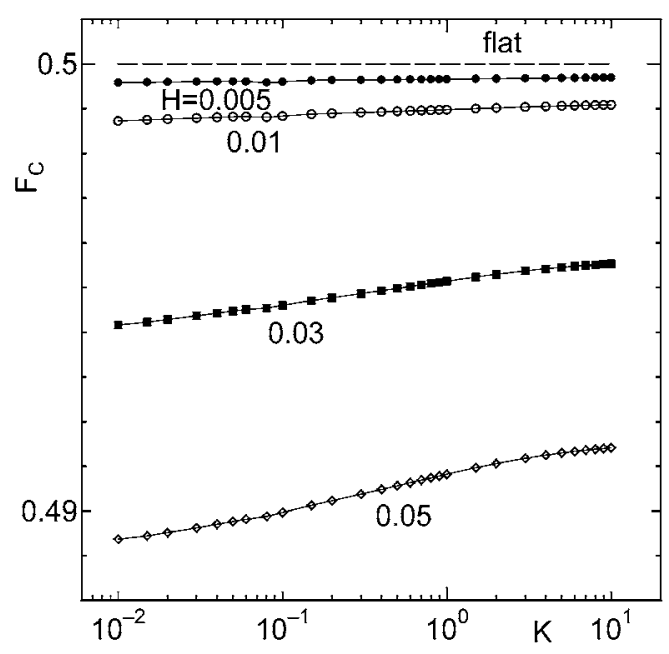

Fig. 3 Flux versus $K$ for Couette flow: parallel groove, $A=B$ $=0.01$.

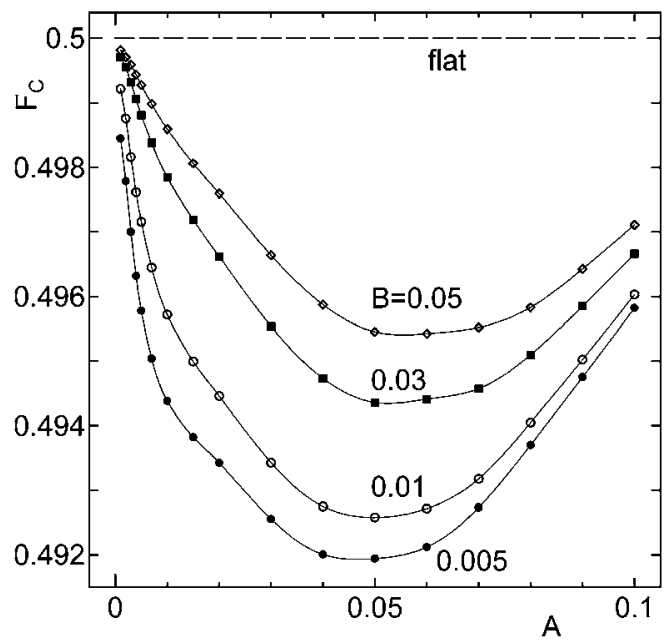

Fig. 4 Flux versus $A$ for Couette flow: normal groove, $H=$ $0.05, K=0.1$.

を, $H=0.05, K=0.1$ 場合に, いくつかの $B$ に対して示 している，いずれの場合も，流量は，下壁が平板のときの值 より小さく, $A \rightarrow 0$ に扔いて平板の值に近づく. また， $A$ が 0 から増加するにつれて, 流量は減少し, 最小値をとった 後, 再び増加する. 流量の最小值は, $A \approx 0.05$ で生じるが, $B$ が小さい程最小值は小さい，流量最小の点では $H \approx A$ で あることから，溝の幅に対し，深さが半分程度のところで最 小値をとることになる.

Fig. 5 は，流量が溝の深さと共にどのように変化するか を， $A=B=0.01$ の場合に，いくつかの $K$ に対し示したもの である.どの場合も，溝の深さを深くしていくと流量は小さ くなるが，ある深さのとき流量は最小值をとり，ある程度深 くなると流量は変化しなくなるという事は興味深い，流量の 最小値は $H \approx 0.01$ ，すなわち $H \approx A$ で生じる．この時，溝 の深さは幅の半分程度である. また， $H \approx 0.02$ より大きいと き，すなわち，溝の幅よりも深さの方が深い溝に扔いては， 流量は殆ど一定となり，溝の深さは流量に関係なくなってく る.

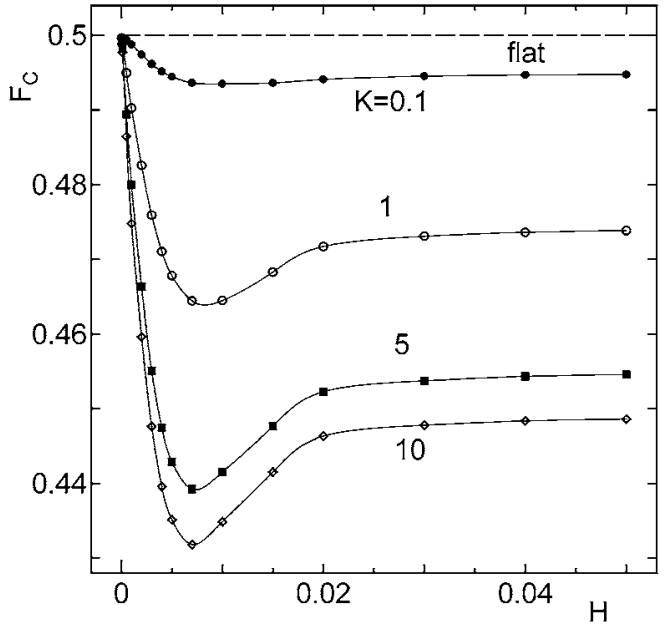

Fig. 5 Flux versus $H$ for Couette flow: normal groove, $A=B$ $=0.01$.

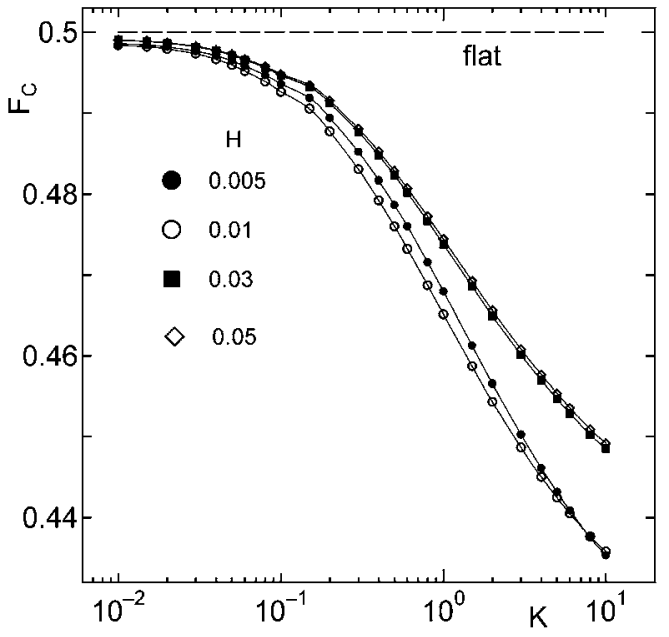

Fig. 6 Flux versus $K$ for Couette flow: normal groove, $A=B$ $=0.01$.

Fig. 6 には， $A=B=0.01$ 場合に，いくつかの $H$ に対 し，流量が $K$ と共にどのように変化するかを示している. この図から分かるように，Kの大きいところでは，流量は 下壁が平板の場合より大きく減少する，また，このとき，H が小さくても，流量に及ぼす効果の大きいことが認められる.

\section{2 ポワゾイユ流}

上壁，下壁共に静止し，チャネルに沿う圧力勾配によって 流れが生じる，いわゆるポワゾイユ流に対する結果を示す.

\subsection{1 平行溝の場合}

Fig. 7 は, $H=0.05, K=0.1$ の場合に, 流量 $F_{\mathrm{P}}$ が $A$ と共 にどのように変化するかを，いくつかの $B$ に対して示した ものである. 溝の幅 $A$ が 0 に近づくにつれて, 下壁が平板 の場合の流量に近づくが， $A$ が小さい間は，平板值より小 さい。この間, $A$ が 0 から増加するに従い, 流量は最小值 をとった後再び増加する. 最小值は $B<A$ の関係を保ちなが ら $A$ が小さくなるにつれて小さくなる.この状況は, 平行 溝のクエット流と似ている，Aが大きくなるにつれて, 相 対的にチャネル幅が下壁を平板としたものより大きくなるこ とから, 流量は点線よりも大きい值を示す. $B$ がどの場合で 


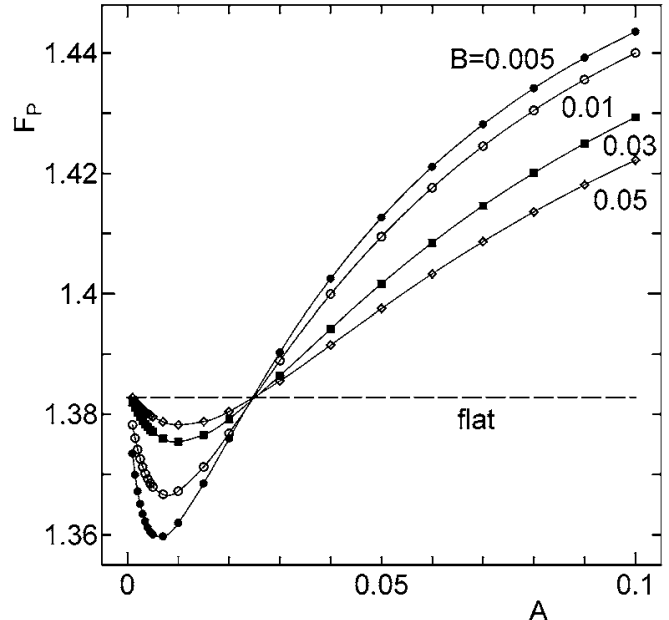

Fig. 7 Flux versus $A$ for Poiseuille flow: parallel groove, $H=$ $0.05, K=0.1$.

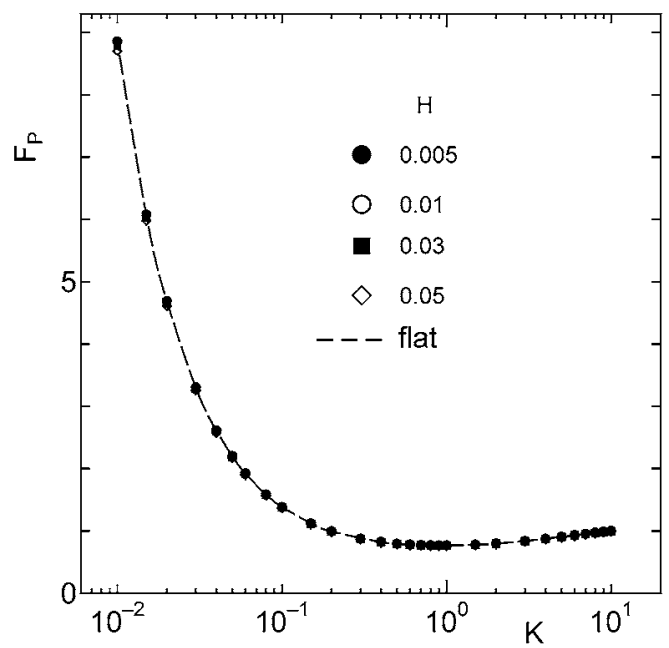

Fig. 8 Flux versus $K$ for Poiseuille flow: parallel groove, $A=$ $B=0.01$.

も， $A \approx 0.025 て ゙ ，$ 点線と同じ值をとるが，このとき $H \approx 2 A$ であることから, 溝の形状は正方形形状であることは興味深 い.

Fig. 8 には, 流量の $K$ に対する変化を，いくつかの $H$ に 対し示している. $A=B=0.01$ の場合である.この図から分 かるように, 流量の $H$ による変化は比較的小さいといえる.

3.2 .2 垂直溝の場合

Fig. 9 は, $H=0.05, K=0.1$ の場合に, $F_{\mathrm{P}}$ の $A$ に対する 変化を, いくつかの $B$ について示したものである. $A$ に対 する流量変化は, クエット流の垂直溝の場合（Fig. 4 参照） と類似している点は興味深い。ポワゾイユ流に扔いても， $A$ $\approx 0.05 て ゙, F_{\mathrm{P}}$ が最小值をとることから，溝の深さが幅の半 分程度のとき流量が最小となることが分かる.

Fig. 10には， $A=B=0.01$ の場合に， $F_{\mathrm{P}}$ が $H$ に対して, ぞのように変化するかを，いくつかの $K$ に対して示してい る.この変化も, クエット流の場合（Fig. 5 参照）とよく似 ている.すなわち, $H \approx A$ で最小值を持つこと, $H \approx 0.02$ よ り大きいとき，すなわち，正方形溝よりも深さの深い溝で



Fig. 9 Flux versus $A$ for Poiseuille flow: normal groove, $H=$ $0.05, K=0.1$.



Fig. 10 Flux versus $H$ for Poiseuille flow: normal groove, $A=$ $B=0.01$.



Fig. 11 Flux versus $K$ for Poiseuille flow: normal groove, $A=$ $B=0.01$. 


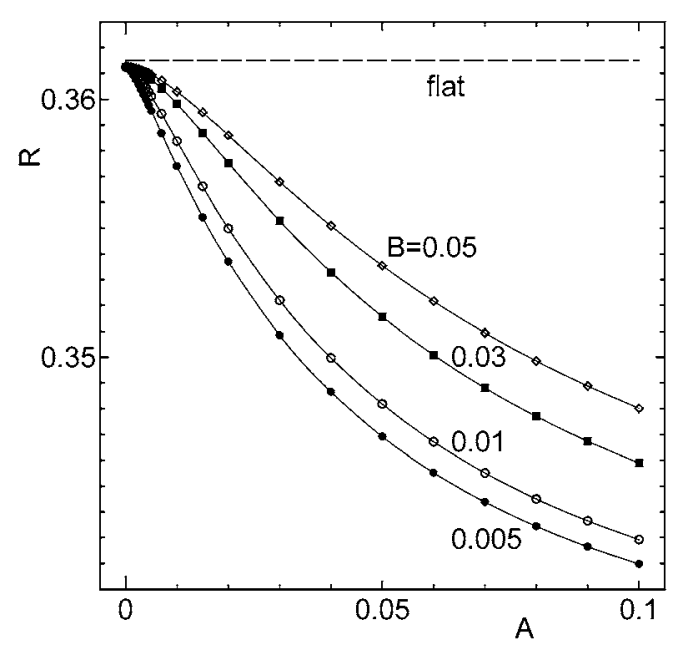

Fig. 12 Ratio of the pressure gradient to the wall speed in case of zero net flux: parallel groove: $H=0.05, K=0.1$.

は，流量変化は殆ど起こらない，ただし，最小値への変化は クエット流程大きくはなく，また， $K$ に対する変化も異な っている.

Fig. 11には，流量の $K$ に対する変化を，いくつかの $H$ に対して示している. $A=B=0.01$ の場合である.これよ り，流量の $H$ による違いは比較的小さいことが分かる.

\section{4. 全流量が 0 の場合の圧力勾配}

クエット流において, 非常に遠く離れたところにあるチャ ネル両端口を閉じた場合には，流れによって誘起される圧力 勾配により逆流が生じ，チャネル内では，クエット流とポワ ゾイユ流の共存する流れとなる。このとき, チャネル断面内 の全流量は 0 となる。この状態での, 圧力勾配と上壁面速 度との関係を式(11)により求める.

Fig. 12は, 平行溝の場合に, 圧力勾配と上壁面速度の比 $R$ の $A$ についての変化を，いくつかの $B$ に対して示したも のである. $H=0.05, K=0.1$ とっている．この図より， $B$ のどの場合に扔いても，一定上壁速度のもとで生ずる圧力勾 配は，下壁が平板の場合よりも小さく，溝の幅が大きくなる につれて，その值はより小さくなる。これは，クエット流で は, Fig. 2 で示されたように, 断面内の流量は下壁が平板の 場合が一番大きく，下壁に溝がある程流れにくくなるが，一 方，ポワゾイユ流においては，Fig. 7 に示したように，Aが 小さいところを除いては, 溝がある程流れやすくなってい る. 従って, 小さい圧力勾配でも, クエット流に見合う逆流 量を流しうることによるものである.

Fig. 13には，垂直溝の場合に誘起される圧力勾配の $A$ に 対する変化を示している. $H=0.05, K=0.1$ の場合である. $A \rightarrow 0$ では平板值に近づくが，その他の $A$ では平板値より大 きく, $A \approx 0.05$ で最大值を持つこと, $B$ が小さい程その值が 大きいことが分かる. $A \approx 0.05 て ゙ R$ は最大值を示すが，この とき溝の幅は深さの 2 倍の場合である. 垂直溝を設けるこ とにより, 全流量 0 の際の圧力勾配が, 下壁が平板の值よ

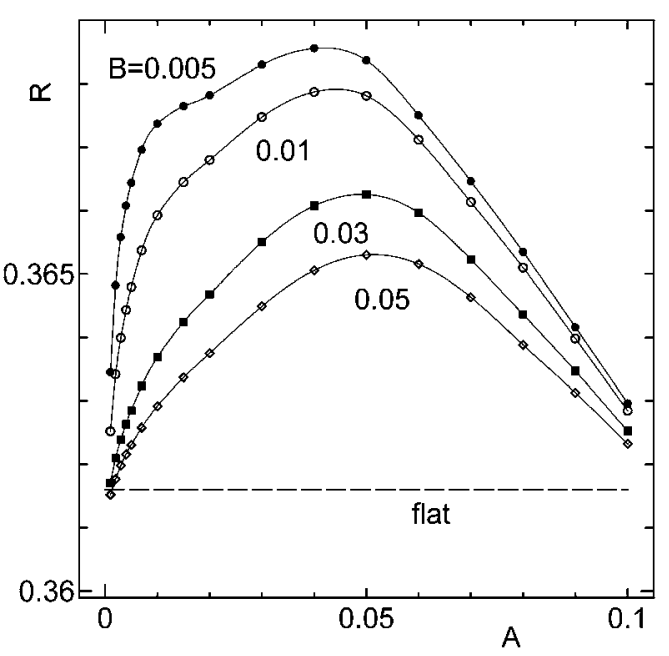

Fig. 13 Ratio of the pressure gradient to the wall speed in case of zero net flux: normal groove: $H=0.05, K=0.1$.

り大きくなることは興味深い．

\section{5. まと め}

上壁面が平らであり, 下壁面に, 流机に平行, あるいは垂 直な矩形溝の凹凸がある場合のクエット流及びポワゾイユ流 の希薄気体の流孔を解析した. 得られた結果をまとめると次 のようになる。

(1) クエット流, ポワゾイユ流共, 垂直溝の場合には, 溝 の深さが幅の半分程度のところで流量が最小值をとり, 深さ が幅程度以上深くなると流量への深さの影響はなくなる. 垂 直溝の場合, クエット流に抢けるクスーセン数の影響は, ク ヌーセン数の大きいところで大きく現れ, 下壁が平板の場合 より流量は大きく減少する，ポワゾイユ流については, ク ヌーセン数の影響は比較的小さく, 下壁が平板の場合からの 流量のずれは小さい.

(2) 平行溝の場合, クエット流, ポワゾイユ流共, (堤の 幅)<(溝の幅) の関係のもとで, 溝の幅が小さいとき, 流量 は, 下壁が平板の場合よりもかなり小さな值をとる.

(3) クエット流, ポワゾイユ流共存の流れに扔いて, チャ ネル内の全流量が 0 となるときに誘起される圧力勾配は, 垂直溝の場合, 溝の深さが幅の半分程度のところで最大値を 持つ.

\section{[文献}

1）宇佐美勝, 藤本哲夫, 加藤征三 : 日本機械学会論文集 B 編, 54 (1988) 1042.

2) 杉山 渉, 澤田 雅, 船木 洋, 中森健治 : 日本機械学会論文 集 B 編，62（1996）1307.

3) H. Sun and M. Faghri: Numerical Heat Transfer, Part A, 43 (2003) 1.

4) T. Sawada, Y. Horie and W. Sugiyama: Vacuum, 47 (1996) 795.

5) K. Yamamoto, H. Takeuchi and T. Hyakutake: Rarefied Gas Dynamics, Monopoli (Bari), Italy, 2004 (AIP, 2005) p. 156.

6) P. L. Bhatnager, E. P. Gross and M. Krook: Phys. Rev., 94 (1954) 511. 